\title{
The asymmetry of rainfall process
}

\author{
YU RuCong ${ }^{1 *}$, YUAN WeiHua ${ }^{2} \&$ LI Jian ${ }^{1,3}$ \\ ${ }^{1}$ LaSW, Chinese Academy of Meteorological Sciences, China Meteorological Administration, Beijing 100081, China; \\ ${ }^{2}$ State Key Laboratory of Numerical Modeling for Atmospheric Sciences and Geophysical Fluid Dynamics (LASG), Institute of Atmospheric \\ Physics, Chinese Academy of Sciences, Beijing 100029, China; \\ ${ }^{3}$ Dali National Climate Observatory, Dali 671003, China
}

Received October 6, 2012; accepted December 4, 2012; published online January 5, 2013

Using hourly station rain gauge data in the warm season (May-October) during 1961-2006, the climatological features of the evolution of the rainfall process are analyzed by compositing rainfall events centered on the maximum hourly rainfall amount of each event. The results reveal that the rainfall process is asymmetric, which means rainfall events usually reach the maximum in a short period and then experience a relatively longer retreat to the end of the event. The effects of rainfall intensity, duration and peak time, as well as topography, are also considered. It is found that the asymmetry is more obvious in rainfall events with strong intensity and over areas with complex terrain, such as the eastern margin of the Tibetan Plateau, the Hengduan Mountains, and the Yungui Plateau. The asymmetry in short-duration rainfall is more obvious than that in long-duration rainfall, but the regional differences are weaker. The rainfall events that reach the maximum during 14:00-02:00 LST exhibit the strongest asymmetry and those during 08:00-14:00 LST show the weakest asymmetry. The rainfall intensity at the peak time stands out, which means that the rainfall intensity increases and decreases quickly both before and after the peak. These results can improve understanding of the rainfall process and provide metrics for the evaluation of climate models. Moreover, the strong asymmetry of the rainfall process should be highly noted when taking measures to defending against geological hazards, such as collapses, landslides and debris flows throughout southwestern China.

rainfall process, asymmetry, rainfall peak, rainfall intensity, rainfall duration time

Citation: $\quad$ Yu R C, Yuan W H, Li J. The asymmetry of rainfall process. Chin Sci Bull, 2013, 58: 1850-1856, doi: 10.1007/s11434-012-5653-6

China is greatly affected by heavy rainfall. Floods and geological disasters caused by excessively heavy rains or longduration heavy rainfall events can exert vast impacts on the socioeconomic development [1,2]. Therefore, the evolution of the rainfall process has always been a hot topic. Restricted by the available data, previous studies about rainfall processes at the hourly time scale have mainly been case studies [3-6], and the climatological investigations on that usually focused on the daily, monthly or even longer time scales [7-11]. However, because rainfall systems are highly inhomogeneous at both the temporal and spatial scale, only datasets with high temporal resolution can reflect the rainfall intensity and the evolution of the rainfall process more precisely [12].

*Corresponding author (email: yrc@cma.gov.cn)
Recently, with the appearance of long-time hourly rainfall data, an increasing number of studies have focused on hourly rainfall characteristics. Based on daily data, the socalled southern flooding and northern drought (SFND) precipitation change over eastern China was found to be contributed by both rainfall frequency and intensity [13,14]. However, Yu et al. [15] pointed out that although the rainfall amount and frequency have significantly increased (decreased) in the mid-lower reaches of the Yangtze River valley (North China) during the last several decades, the hourly rainfall intensity has decreased (increased). Their results also showed that the SFND pattern could mostly be attributed to changes in precipitation of moderate and low intensity. They also showed that neither the frequency nor the amount of strong intensity rainfall has exhibited the SFND pattern, which also differed from the previous results 
based on daily data $[13,14]$. The interdecadal changes in rainfall characteristics derived from hourly rainfall data provide new insights for understanding the mechanisms of the SFND. Moreover, studies on the diurnal cycles of rainfall have also improved the understanding of the rainfall's formation and evolution. It has been found that summer rainfall over contiguous China has pronounced diurnal variations with considerable regional features [16-19]. Over southern and northeastern China, summer rainfall at most stations peaks in late afternoon; over southwestern China, hourly rainfall peaks around midnight. The regionally averaged diurnal variation of summer precipitation in central eastern China is characterized by two comparable peaks in early morning and late afternoon. Further studies [20-24] have revealed that long-duration rainfall events usually reach a maximum around early morning and that short-duration events reach a maximum around late afternoon. The late afternoon peak of short-duration rainfall events may be explained by the diurnal variation of low-level atmospheric stability caused by solar heating, and the earlymorning peak may be related to large-scale circulations, the longwave radiative cooling effect at the top of clouds and the life cycle of meso-scale convective systems.

Previous studies have rarely focused on the climatological features of the evolution of the rainfall process at the hourly time scale, so we know little about the evolution of rainfall events from beginning to end in a climatological view. In this study, by compositing rainfall events centered on the maximum hourly rainfall amount and by considering the rainfall intensity, duration and peak time, as well as the topography, we analyzed the climatological features of the rainfall process's evolution. These results can further our understanding of the rainfall process and provide a new method for studying rainfall evolution.

\section{Data and method}

A dataset of hourly rain gauge records from 535 stations covering mainland China for the period 1961 to 2006 was used in this study. Detailed information can be found in $\mathrm{Yu}$ et al. [15], Yuan et al. [22] and $\mathrm{Li}$ et al. [23]. The records from 392 stations between $95^{\circ}-122^{\circ} \mathrm{E}$ and $20^{\circ}-40^{\circ} \mathrm{N}$ (Figure 1) were analyzed in this study. Considering the density of stations, we mainly focused on the regions east of $102^{\circ} \mathrm{E}$. According to the different features of the rainfall processes' evolution, we defined two representative regions: the western $\left(102^{\circ}-108^{\circ} \mathrm{E}, 22^{\circ}-37^{\circ} \mathrm{N}\right)$ and eastern $\left(112^{\circ}-122^{\circ} \mathrm{E}, 2^{\circ}-\right.$ $37^{\circ} \mathrm{N}$ ) regions.

A rainfall hour is defined as an hour with $0.1 \mathrm{~mm}$ or more of accumulated precipitation. And a rainfall event is defined as continuous rainfall without any intermittence or, at most, a 5-h pause. The number of hours between the start and the end of an event is defined as the duration time of the rainfall event. Because the rainfall lasting less than or equal

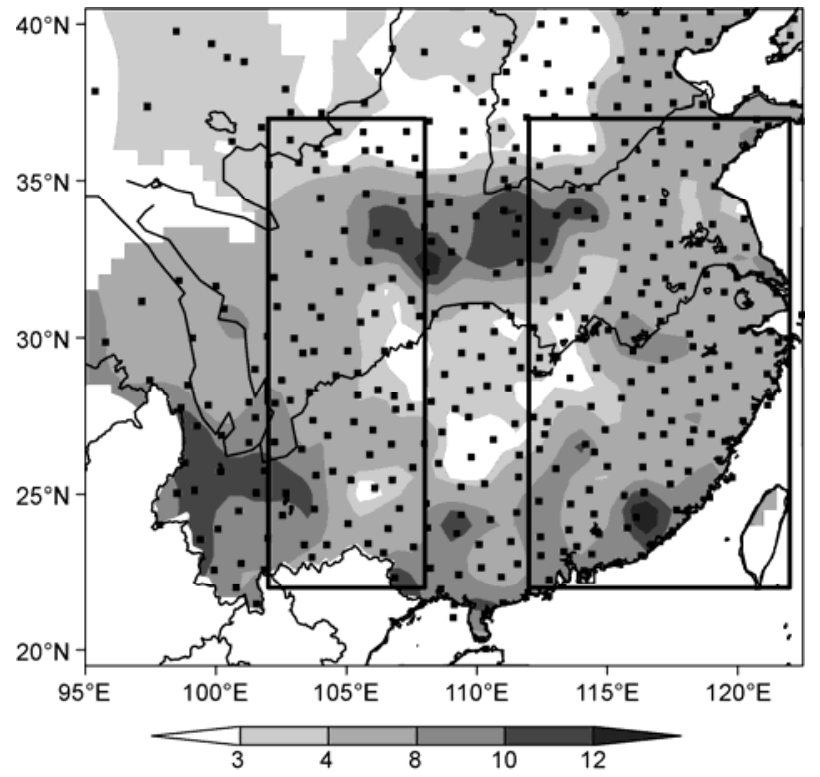

Figure 1 Locations of 392 rain gauge stations and the e-folding decay rainfall intensity (shaded, units: $\mathrm{mm} \mathrm{h}^{-1}$ ). Two subregions, the western region $\left(102^{\circ}-108^{\circ} \mathrm{E}, 22^{\circ}-37^{\circ} \mathrm{N}\right)$ and eastern region $\left(112^{\circ}-122^{\circ} \mathrm{E}, 22^{\circ}-37^{\circ} \mathrm{N}\right)$ are outlined for regional average.

to $6 \mathrm{~h}$ mainly peaks in late afternoon and that lasting more than $6 \mathrm{~h}$ primarily reaches the hourly maximum in early morning [22,23], a long-duration rainfall event is defined as lasting more than $6 \mathrm{~h}$ and a short-duration rainfall event as lasting 1 to $6 \mathrm{~h}$.

The raining time before the peak is referred to as the hours between the beginning and peaking time of a rainfall event, whereas the raining time after the peak is defined as the hours between the peaking and ending time of a rainfall event. All the rainfall events in the warm season (May-October) during 1961-2006 are composed centered on the peak time (time zero).

$\mathrm{Yu}$ and $\mathrm{Li}$ [25] showed that the distributions of rainfall with hourly intensity approximately follow an exponential decay pattern. Thus, the accumulated rainfall amout of intensity $I(R(I))$ can be fitted by $R(I)=A \cdot \mathrm{e}^{-B \cdot I}$. The parameters $A$ and $B$ are determined by the least squares fitting of $\ln [R(I)]=\ln A-B \cdot I$. According to $\mathrm{Yu}$ and $\mathrm{Li}$ [25], the e-folding decay intensity $(1 / B)$ is comparable to the 95th percentile rainfall intensity in the widely used percentile method. Thus, the e-folding decay intensity is defined as the threshold that divides the hourly weak and intense rainfall.

\section{The asymmetry of the rainfall process}

Figure 2(a) shows the ratio of the rainfall frequency (RF) before and after the peak to that at the peak time averaged between $102^{\circ}-122^{\circ} \mathrm{E}$ and $20^{\circ}-40^{\circ} \mathrm{N}$. As implied in this figure, both the intense (dotted solid lines) and weak (dashed lines with circles) rainfall events are asymmetric before and after 
the peak time (time zero). The RF before the peak is much smaller than that after the peak, which means the rainfall events usually reach the maximum quickly and experience a relatively gradual retreat to the end of the event. Compared with the weak rainfall events, the intense events show more significant asymmetry. For weak rainfall, the RF before the peak to that after the peak is approximately 0.706 , while that in the intense rainfall is approximately 0.632 . The differences of RF between the $12 \mathrm{~h}$ before and after the peaks is significant at the $10 \%$ confidence level according to Student's $t$-test, and it is mainly contributed by the $8 \mathrm{~h}$ closest to the peak, but the counterpart in weak rainfall is not significant at that level.

The rainfall intensity, different from the frequency, is quite prominent at the peak time and increases/decreases rapidly before/after the peak (Figure 2(b)). As shown in Figure $2(\mathrm{c})$, at $1 \mathrm{~h}$ before the peak, the intense rainfalls
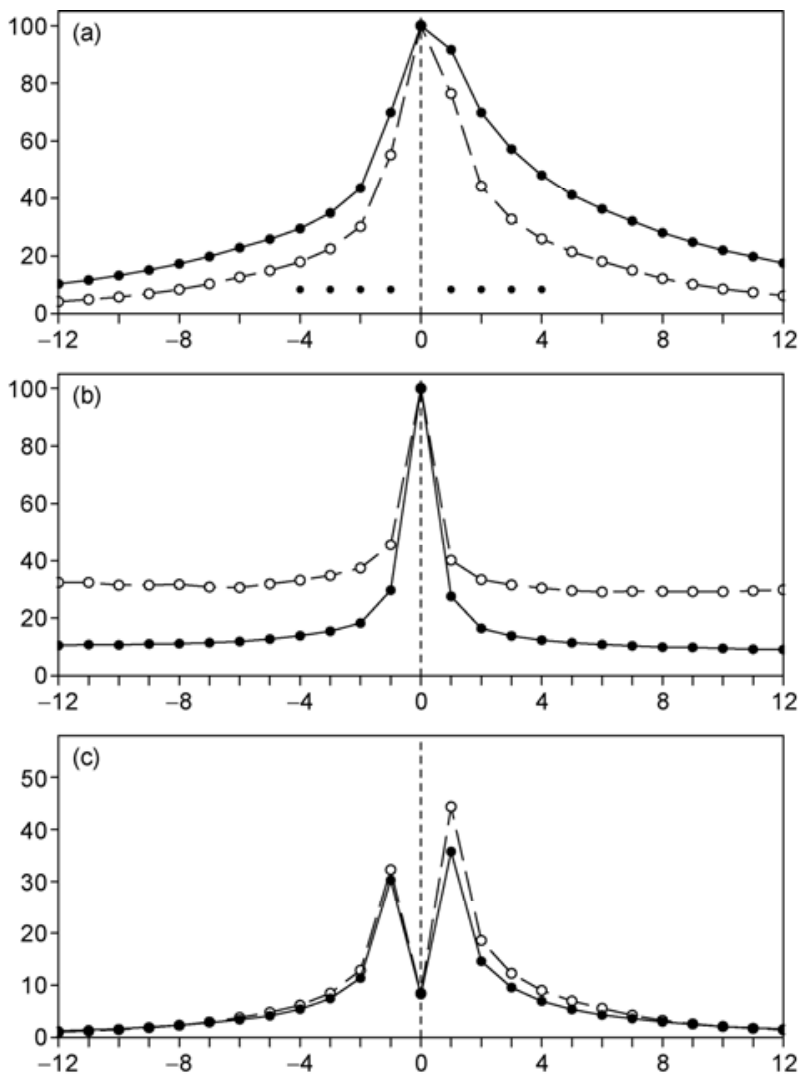

Figure 2 The ratio (units: \%) of composed rainfall (a) frequency and (b) intensity before and after the rainfall peak to that at the peak time (time zero) averaged in $102^{\circ}-122^{\circ} \mathrm{E}, 20^{\circ}-40^{\circ} \mathrm{N}$ in the warm season (May-October) during 1961-2006. The dotted solid lines (dashed lines with circles) are for the intense rainfall (weak rainfall). The differences of frequency before and after the peak time of intense rainfall in (a) is significant at the $10 \%$ confidence level according to Student's $t$-test and the time when rainfall accounts for more than $10 \%$ of the differences are marked by black dotes at the bottom of (a). (c) Same as in (a), but for the percentages of rainfall with intensity greater than $30 \%$ of that at the peak time to the total frequency at each time (except time zero); the percentage at time zero represents the rainfall with intensity greater than $30 \%$ of that at the peak time to total rainfall at both $1 \mathrm{~h}$ before and after the peak time. (dotted solid lines), which can reach $30 \%$ of the intensity at the peak, are less than a third of the total. At $1 \mathrm{~h}$ after the peak, the ratio is slightly larger, but still only accounts for approximately $35.8 \%$. Moreover, the rainfall events, with the intensity at $1 \mathrm{~h}$ before and after the peak being greater than $30 \%$ of the intensity at the peak simultaneously, occupy less than one tenth of the total rainfall. Although the increasing/decreasing speed before/after the peak in weak rainfall (dashed lines with circles) is slower than that in the intense rainfall, they share the similar trends.

As illustrated in Figure 2, the asymmetry before and after the peak in rainfall frequency is greater than that in the intensity. In the following analyses, we mainly focus on the rainfall frequency. To analyze the regional features of the asymmetry of rainfall processes, Figure 3(a) and (b) presents the distributions of the RF before and after the peak. Consistent with Figure 2, the asymmetry in the intense rainfall is greater than that in the weak rainfall. Moreover, we can find in Figure 3 that the asymmetry of rainfall processes is higher over southwestern China than that over southeastern China. The demarcation line between these two regions lies approximately $110^{\circ} \mathrm{E}$ and the regional discrepancy is more obvious in the intense rainfall. There are regions with great asymmetry over the Hengduan Mountains and the Yungui Plateau, where the RF before and after the peak is less than 0.4. Meanwhile, the asymmetry of rainfall processes is weak along the coastlines, which means that the rainfall frequency of intense rainfall before the peak is similar to that after the peak.

Because the regional differences are more obvious in the intense rainfall, we further compared the RF of intense rainfall at each hour before and after the peak to the peak time averaged in the western $\left(102^{\circ}-108^{\circ} \mathrm{E}, 22^{\circ}-37^{\circ} \mathrm{N}\right)$ and eastern $\left(112^{\circ}-122^{\circ} \mathrm{E}, 22^{\circ}-37^{\circ} \mathrm{N}\right)$ region. As shown in Figure 3(c), the RF before the peak is smaller in the western region (dotted solid lines) than that in the eastern region (dashed lines with circles), whereas the RF after the peak is larger in the western region. The differences of RF before and after the peak in the western region are significant at the $5 \%$ confidence level, whereas those in the eastern region are not. Moreover, the regional discrepancy can be mainly attributed to the rainfall before the peak.

\section{The impact of duration and peak time to the asymmetry of the rainfall process}

Based on previous studies, the short- and long-duration rainfall used to have different circulation patterns, and the diurnal features and spatial distributions are different [20-22]. This feature motivated us to analyze the asymmetry of rainfall processes with different duration times.

Figure 4 depicts the RF before and after the peak of the two kinds of rainfall. As shown, the asymmetry in the short-duration rainfall (Figure 4(a) and (b)) is stronger than 

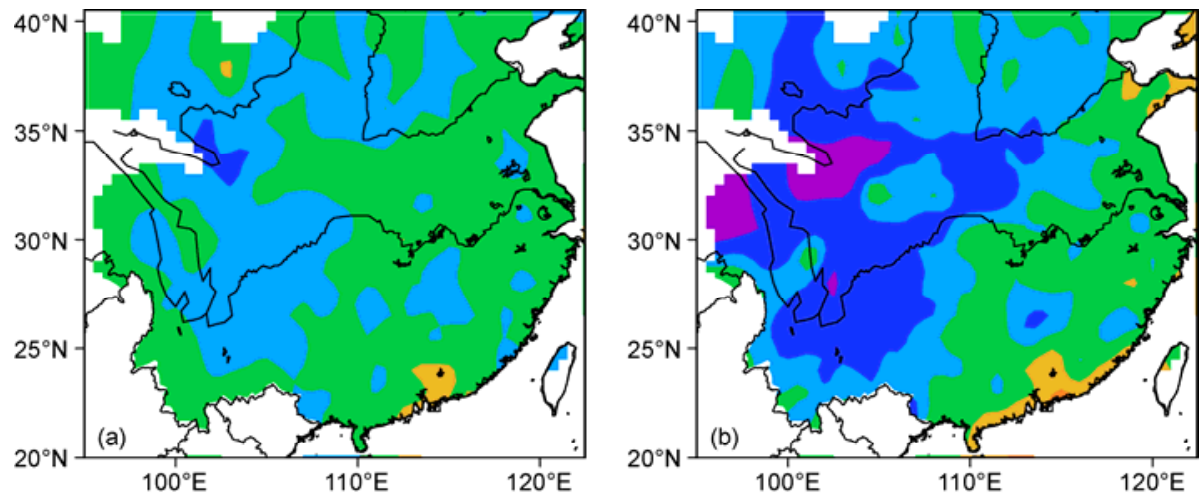

$\begin{array}{llllll}0.4 & 0.6 & 0.7 & 0.8 & 0.9 & 1\end{array}$

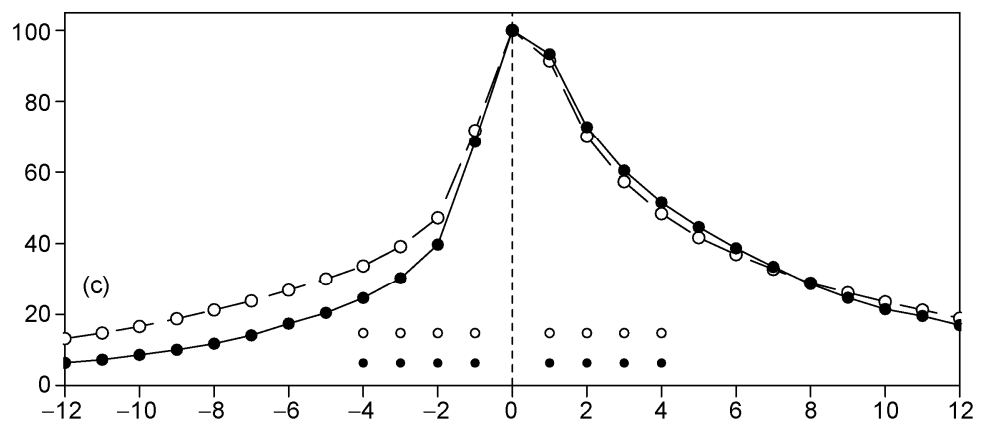

Figure 3 The spatial distribution of the ratio of frequency of weak (a) and intense (b) rainfall before the peak to that after the peak. (c) Same as in Figure 2(a) (units: \%), but for the regional averaged intense rainfall over the western (dotted solid line) and eastern (dashed line with circles) regions. The differences of intense rainfall frequency before and after the peak time over the western and eastern region are significant at the $10 \%$ confidence level according to Student's $t$-test, and the times when rainfall accounts for more than $10 \%$ of the differences are marked by black dots (western region) and circles (eastern region) at the bottom of (c).

that in the total rainfall (Figure 3). The regional averaged $\mathrm{RF}$ is approximately 0.55 for the weak short-duration rainfall, but it can reach 0.46 in the intense rainfall. However, the regional differences are relatively small. The RFs of the western and the eastern region in weak short-duration rainfall are 0.53 and 0.54 . The differences of the RF in intense rainfall are slightly larger but still are approximately 0.04, as can also be seen in Figure 4(e). Even for the intense short-duration rainfall, the variations in RF in the western region (solid line) at each hour are nearly the same as those in the eastern region (dashed line). However, the regional differences of RF in short-duration rainfall mainly exist in the period after the peak, which is distinct from that in the total intense rainfall (Figure 3(c)).

The spatial distribution of RF of the long-duration rainfall (Figure 4(c) and (d)) resembles that of the total rainfall (Figure 3(a) and (b)). The correlation coefficient of the spatial distribution between the weak (intense) long-duration and weak (intense) total rainfall can reach 0.99 (0.95). As a result, the regional differences in the asymmetry of rainfall processes are mainly contributed by the long-duration rainfall. Moreover, the near symmetric rainfall processes along the coastlines are also contributed to by the long-duration rainfall. According to the evolution of rainfall processes over the eastern and western regions (Figure 4(e)), the re- gional differences are attributed to the rainfall before the peak, which means that it takes less time for the rainfall to reach the maximum over the western region than it does over the eastern region.

Because rainfall processes may vary at diurnal time scales, we investigated the potential impact of the peak time to the asymmetry of the rainfall process by employing the intense long-duration rainfall which shows the highest regional dependence. Figure 5 shows the composed the evolution of rainfall processes with different peak times averaged between $102^{\circ}-122^{\circ} \mathrm{E}$ and $20^{\circ}-40^{\circ} \mathrm{N}$. We can find that the highest asymmetry appears in the rainfall events peaking during 20:00-02:00 LST (dashed line with circles) and the second one during 02:00-08:00 LST (dotted line with open rectangles). The RF before the peak only accounts for approximately $58 \%(62 \%)$ of the counterpart after the peak for the rainfalls peaking at 20:00-02:00 (02:00-08:00) LST, and the differences before and after the peak during these two period are both significant at the $1 \%$ confidence level. The weakest asymmetry occurs in rainfall peaking at 08:0014:00 LST (dashed line with solid rectangles) and is not significant.

By merging the first two periods with the highest rainfall asymmetry, Figure 6 illustrates the distributions of RF before the peak to that after the peak. It can be found that the 

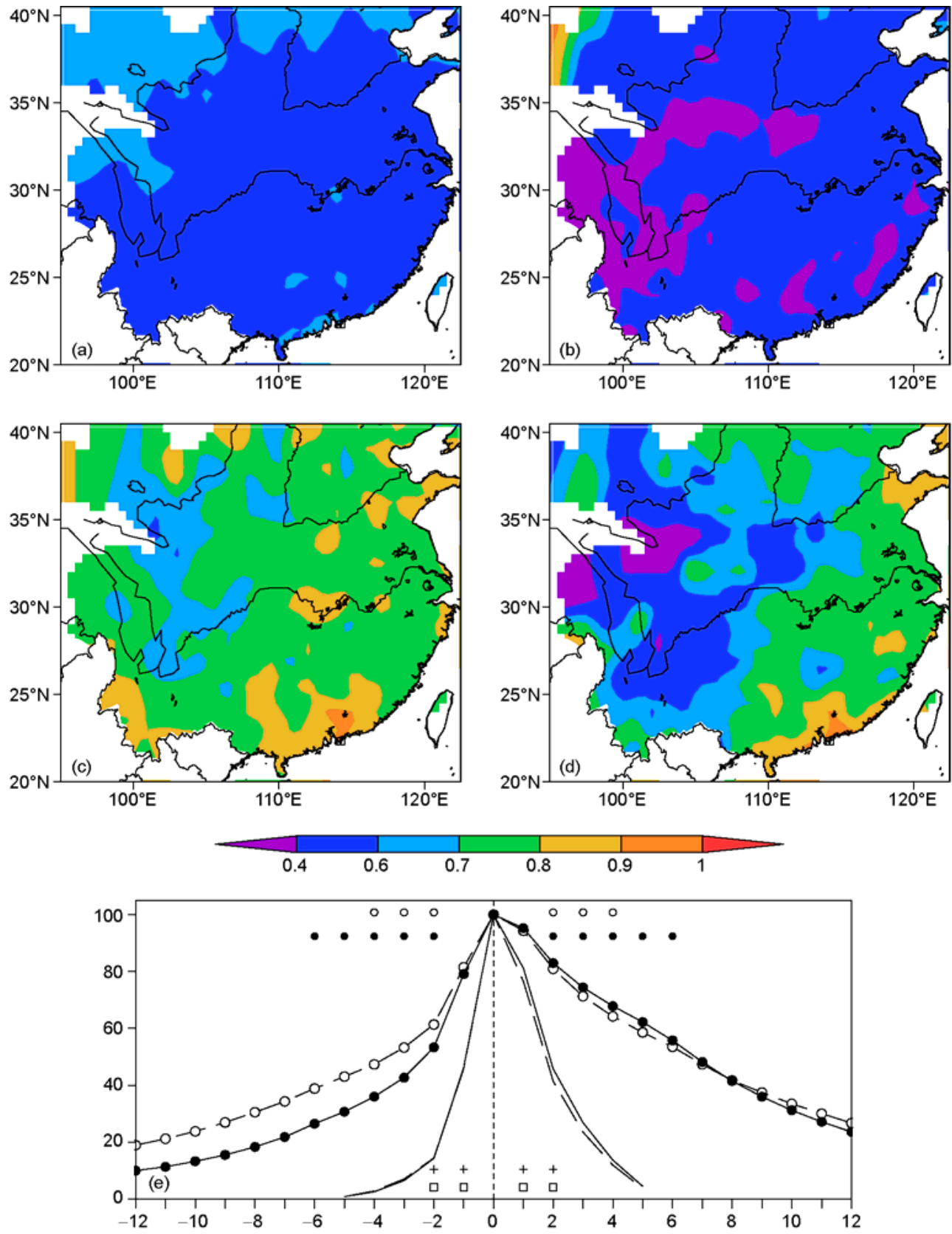

Figure 4 (a) and (b) ((c) and (d)) Same as in Figure 3(a) and (b), but for the short- (long-) duration rainfall. (e) Same as in Figure 2(a) (units: \%), but for the regional averaged long-duration intense rainfall over the western (dotted solid line) and eastern (dashed line with circles) regions and the short-duration intense rainfall over the western (solid line) and eastern (dashed line) regions. The differences of intense and weak rainfall frequency before and after the peak are significant at the $10 \%$ confidence level according to Student's $t$-test. The times when rainfall accounts for more than $10 \%$ (30\%) of the differences in long- (short-) duration rainfall are marked at the top (bottom) of (e). The dots (circles) represent the long-duration intense rainfall over the western (eastern) region and the rectangles and crosses are for the short-duration rainfall over these two regions.

regional discrepancy is even more obvious (Figure 6) when compared with that of the all-day intense long-duration rainfall (Figure 4). The strong asymmetry is primarily located in the upper reaches of the Yangtze and Yellow Rivers, especially the Yungui Plateau and the Hengduan Mountains. The enhanced asymmetry is partly due to the enlargement of discrepancy before the peak, but it can also be attributed to the widening gap after the peak (Figure 6(b)), which is verified by the rainfall intensity (figure omitted). Although the evolution of the intensity of intense long-duration rainfall peaking during 20:00-08:00 LST presents a similar trend to that of total rainfall (Figure 2(c)), the intensity will be maintained longer, as exemplified by the intensity at $2 \mathrm{~h}$ after the peak. For the total rainfall, only $15 \%$ of the rainfall events can preserve $30 \%$ of the intensity at peak time, but the number is approximately $20 \%$ for the intense 


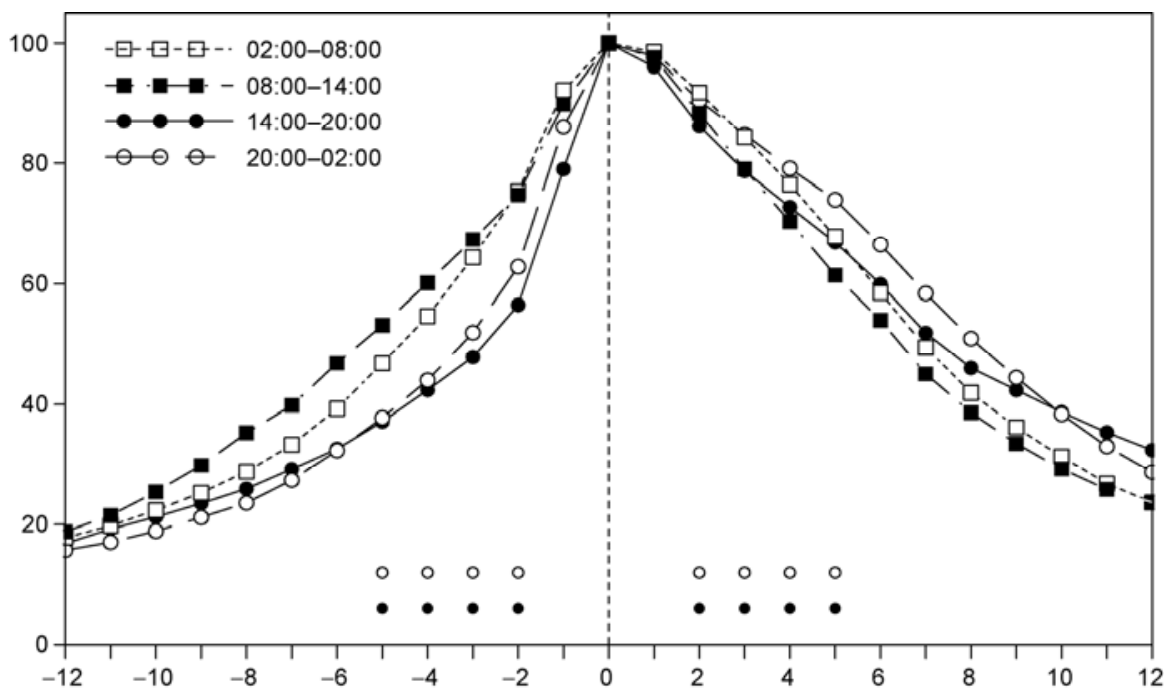

Figure 5 Same as in Figure 2(a), but for the regional averaged long-duration intense rainfall with peaks between 02:00-08:00 LST (rectangles with dotted line), 08:00-14:00 LST (solid rectangles with dashed line), 14:00-20:00 LST (dotted solid lines) and 20:00-02:00 LST (circle with dashed line) over $102^{\circ}-122^{\circ} \mathrm{E}, 20^{\circ}-40^{\circ} \mathrm{N}$ (units: \%). The differences of rainfall frequency before and after the peak in rainfall events peaking at 14:00-20:00 and 20:00-02:00 LST are significant at the 5\% confidence level according to Student's $t$-test. The times when rainfall accounts for more than 5\% of the differences are marked at the bottom of the figure, and the dots (circles) represent rainfall peaking at 14:00-20:00 (20:00-02:00) LST.
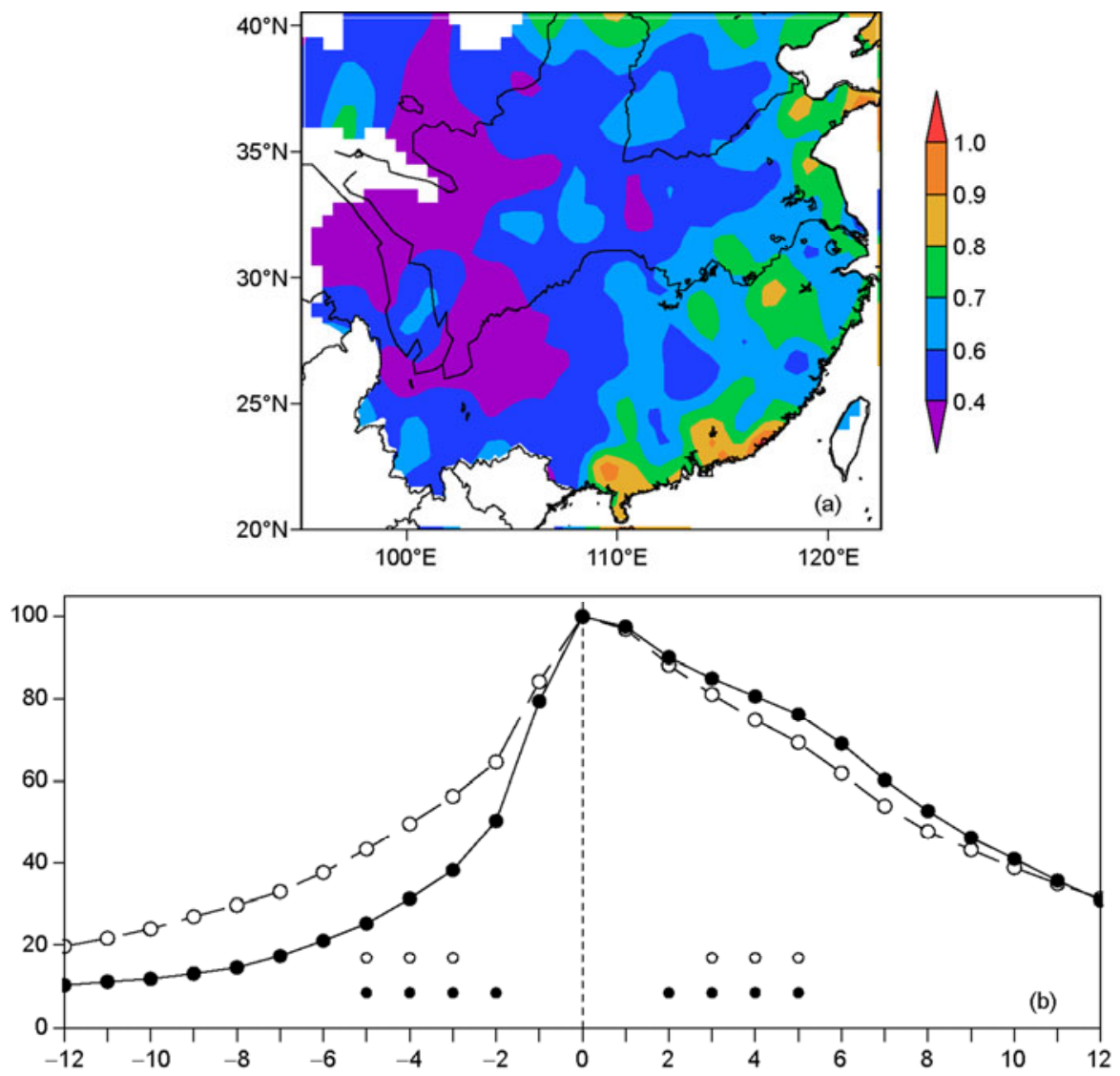

Figure 6 (a) Same are in Figure 3(a), but for the long-duration intense rainfall peaking at 14:00-02:00 LST. (b) Same as in Figure 2(a) (units: \%), but for the regional averaged long-duration intense rainfall peaking at 14:00-02:00 LST over the western (dotted solid line) and eastern (dashed line with circles) regions. The differences of rainfall frequency before and after the peak over both the western and eastern regions are significant at the 5\% confidence level according to Student's $t$-test. The times when rainfall accounts for more than $10 \%$ of the differences are marked at the bottom of (b) and the dots (circles) represent the western (eastern) region. 
long-duration rainfall peaking during 20:00-08:00 LST.

\section{Summary and discussions}

Using the hourly rain gauge data in warm seasons during 1961-2006, we analyzed the asymmetry of the rainfall process by composing them centered on the peak time. The major conclusions are summarized as follows. (1) Remarkable asymmetry has been found in the evolution of the rainfall process. It takes relatively less time for a rainfall event to reach the peak than from the peak to the end. The increase (decrease) of rainfall intensity is fast before (after) the peak. (2) The asymmetry of the rainfall process is regionally dependent, being more obvious over the western region, especially over the eastern edge of the Tibetan Plateau, the Hengduan Mountains and the Yungui Plateau, and quite weak along the southeastern coastlines. (3) The asymmetry of the rainfall process is also influenced by the duration and the peak time of rainfall events. The asymmetry is stronger in the short-duration rainfall, but with less regional differences, and opposite in the long-duration rainfall. The rainfall peaking at 20:00-02:00 LST shows the highest asymmetry and the rainfall peaking in 08:00-14:00 LST shows the weakest.

This work can enrich our knowledge about the evolution of the rainfall process and provide metrics for the evaluation of climate models; it also provides a new method for studying the rainfall process. However, further investigation into the evolution of the rainfall process is required to gain physical understanding and to improve rainfall prediction. Nevertheless, the present study has shown that the asymmetry is greatly influenced by the complex topography of southwestern China. In addition, the regions where the rainfall process shows strong asymmetry are also regions that bear a high risk of geological hazards, such as collapses, landslides and debris flows, according to Zhang et al. [26]. The quantitative relationship between rainfall and these hazards can only be obtained when more data about geological hazards are available. However, the rainfall process with strong asymmetry should be given considerable attention when defending against geological hazards over southwestern China.

This work was supported by the National Basic Research Program of China (2010CB951902) and the National Natural Science Foundation of China (41221064)

1 Tao S Y. The Heavy Rainfall in China (in Chinese). Beijing: Science Press, 1980

2 Ding Y H. Study of the Long-Duration Heavy Rainfall Over the Huaihe and Yangtze River Valley in 1991 (in Chinese). Beijing: China
Meterological Press, 1993

3 Li K, Xu Y P, Yu R C, et al. Comparative studies of three types of heavy rainstorms associated with the Meiyu front by numerical simulations (in Chinese). Chin J Atmos Sci, 2005, 29: 236-248

4 Sun J H, Zhang X L, Qi L L, et al. A study of vortex and its mesoscale convective system during China heavy rainfall experiment and study in 2002 (in Chinese). Chin J Atmos Sci, 2004, 28: 675-691

5 Cui C G. Sensitivity test for mesoscale moisture initial value in numerical model for a severe rainfall process (in Chinese). Meteorol Monthly, 2000, 26: 3-7

6 Ding Y H, Zhang Q M, Hu G Q. Analysis of the large-scale circulation features and synoptic systems in East Asia during the intensive observation period of GAME/HUBEX. J Meteorol Soc Jpn, 2001, 79: 277-300

7 Chen T C, Wang S Y, Huang W R, et al. Variation of the East Asian summer monsoon rainfall. J Clim, 2004, 17: 744-762

8 Ding Y H, Chan J C. The East Asian summer monsoon: An overview. Meteorol Atmos Phys, 2005, 89: 117-142

9 Lu R Y. The decadal variation of precipitation over North China and SST over tropical East Pacific. Chin Sci Bull, 2005, 50: 1131-1135

10 Huang D Q, Zhu J, Kuang X Y. Decadal variation of different durations of continuous Meiyu precipitation and the possible cause. Chin Sci Bull, 2011, 56: 424-439

11 Li W B, Wang D X, Lei T, et al. High-frequency atmospheric variability over South China Sea as depicted by TRMM and QuikSCAT. Acta Oceanol Sin, 2011, 30: 46-52

12 Trenberth K E, Dai A, Rasmussen R M, et al. The changing character of precipitation. Bull Amer Meteorol Soc, 2003, 84: 1205-1217

13 Zhai $\mathrm{P}$, Zhang $\mathrm{X}$, Wan $\mathrm{H}$, et al. Trends in total precipitation and frequency of daily precipitation extremes over China. J Clim, 2005, 18: 1096-1108

14 Li H M, Zhou T J, Yu R C. Analysis of July-August daily precipitation chatacteristics variation in eastern China during 1958-2000 (in Chinese). Chin J Atmos Sci, 2008, 32: 358-370

$15 \mathrm{Yu} \mathrm{R} \mathrm{C,} \mathrm{Li} \mathrm{J,} \mathrm{Yuan} \mathrm{W} \mathrm{H,} \mathrm{et} \mathrm{al.} \mathrm{Changes} \mathrm{in} \mathrm{characteristics} \mathrm{of}$ late-summer precipitation over eastern China in the past 40 years revealed by hourly precipitation data. J Clim, 2010, 23: 3390-3396

16 Wang F C, Yu R C, Chen H M, et al. The characteristics of rainfall diurnal variation over the Southwestern China. Torr Rain Dis, 2011, 30: $117-121$

17 Yu R C, Zhou T J, Xiong A, et al. Diurnal variations of summer precipitation over contiguous China. Geophys Res Lett, 2007, 34: L01704

18 Yin S Q, Chen D L, Xie Y. Diurnal variations of precipitation during the warm season over China. Int J Climatol, 2009, 29: 1154-1170

19 Li W B, Luo C, Wang D X, et al. Diurnal variations of precipitation over the South China Sea. Meteorol Atmos Phys, 2010, 109: 33-46

20 Chen H M, Yu R C, Li J, et al. Why nocturnal long-duration rainfall presents an eastward-delayed diurnal phase of rainfall down the Yangtze River Valley. J Clim, 2010, 23: 905-917

21 Yu R C, Xu Y P, Zhou T J, et al. Relation between rainfall duration and diurnal variation in the warm season precipitation over central eastern China. Geophys Res Lett, 2007, 34: L13703

22 Yuan W H, Yu R C, Chen H M, et al. Subseasonal characteristics of diurnal variation in summer monsoon rainfall over central eastern China. J Clim, 2010, 23: 6684-6695

23 Li J, Yu R C, Yuan W H, et al. Changes in duration-related characteristics of late-summer precipitation over eastern China in the past 40 years. J Clim, 2011, 24: 5683-5690

24 Li J, Yu R C, Wang J. Diurnal variations of summer precipitation in Beijing. Chin Sci Bull, 2008, 53: 1933-1936

25 Yu R C, Li J. Hourly rainfall changes in response to surface air temperature over eastern contiguous China. J Clim, 2012, 25: 6851-6861

26 Zhang C S, Zhang Y C, Zhang L H. Dager assessment of collapses, landslides and debris flows of geological hazards in China (in Chinese). J Geomech, 2004, 10: 27-32

Open Access This article is distributed under the terms of the Creative Commons Attribution License which permits any use, distribution, and reproduction in any medium, provided the original author(s) and source are credited. 